\title{
GRAMMATIC INNOVATIONS IN THE MODERN POETRY AS MANIFISTATION OF LINGUISTIC CREATIVITY
}

\author{
Natalya A. Fateeva \\ V.V. Vinogradov Russian Language Institute, Russian Academy of Sciences, Moscow, Russia
}

\begin{abstract}
The paper deals with the general issues of linguistic creativity and outlines that it manifests itself most clearly in poetic text. We analyze the neological forms of poetry from this viewpoint and point out that they resulted from the interaction of the word-formative and grammatical levels of language. We also systematize the models of derivation from such parts of speech that were not previously involved in the process of word formation, for example, the nouns derived from pronouns, the imperative forms with nonstandard patterns of government, reflexive verbs with a modified actant structure, short adjectives formed from relative complete forms and the forms of comparative adjectives. The revealed productivity and paradigmatic nature of the neological formations allow asserting that the models for their derivation are potentially embedded in the language, which enables each of them to realize themselves in individual author's forms. At the same time, the contextual analysis has shown that innovations acquire the creative function in texts. The study confirms that language creativity is a special category of linguistic poetics and an area for studying those individual author's transformations in the field of poetic speech that serve as the basis for renovation and expanding the very system of poetic language.
\end{abstract}

Key words: modern poetry, word formation, grammar, innovations, pronominal derivatives, reflexive property, short adjectives, degree of comparison.

Citation. Fateeva N.A. Grammatic Innovations in the Modern Poetry as Manifistation of Linguistic Creativity. Vestnik Volgogradskogo gosudarstvennogo universiteta. Seriya 2, Yazykoznanie [Science Journal of Volgograd State University. Linguistics], 2018, vol. 17, no. 2, pp. 44-52. (in Russian). DOI: https://doi.org/10.15688/jvolsu2.2018.2.5

УДК 811.161.1’373.611

Дата поступления статьи: 06.02.2018

ББК 81.411.2-20 Дата принятия статьи: 02.04.2018

\section{ГРАММАТИЧЕСКИЕ ИННОВАЦИИ В СОВРЕМЕННОЙ ПОЭЗИИ КАК ПРОЯВЛЕНИЕ ЛИНГВОКРЕАТИВНОСТИ}

\author{
Наталья Александровна Фатеева \\ Институт русского языка им. В.В. Виноградова РАН, г. Москва, Россия
}

\begin{abstract}
Аннотация. В статье обсуждаются общие вопросы языковой креативности и делается вывод о том, что лингвокреативность проявляет себя наиболее явно в поэтическом тексте. С этой точки зрения анализируются появившиеся на современном этапе развития поэзии новообразования, которые стали результатом взаимодействия словообразовательного и грамматического уровней языка, и систематизируются модели деривации от таких частей речи, которые раньше не были включены в процесс словообразования. К таким дериватам относятся существительные, образованные от местоимений, императивные формы с нестандартным управлением, возвратные глаголы с измененной актантной структурой, краткие прилагательные, образованные от относительных полных форм, а также формы сравнительной степени прилагательных. Обнаруженные нами продуктивность и парадигматичность этих новообразований позволяют утверждать, что модели их деривации потенциально заложены в языке, это дает возможность каждому из них реализовать себя в индивидуально-авторских формах. В то же время контекстный анализ показал, что инновации приобретают в тексте креативную функцию. В целом исследование подтверждает, что языковая креативность является особой категорией лингвистической поэтики как области изучения тех индивидуально-авторских преобразова-
\end{abstract}


Н.A. Фатеева. Грамматические инновации в современной поэзии как проявление лингвокреативности

ний в области художественной речи, которые служат основой обновления и расширения самой системы поэтического языка.

Ключевые слова: современная поэзия, словообразование, грамматика, инновации, отместоименные дериваты, возвратность, краткие прилагательные, степень сравнения.

Цитирование. Фатеева Н. А. Грамматические инновации в современной поэзии как проявление лингвокреативности // Вестник Волгоградского государственного университета. Серия 2, Языкознание. - 2018. T. 17, № 2. - C. 44-52. - DOI: https://doi.org/10.15688/jvolsu2.2018.2.5

\section{Введение}

В современной лингвистике все больше работ посвящается языку современной поэзии. Рассматриваются его особенности в контексте истории языка [Зубова, 2000; 2010], изучаются активные процессы, происходящие в нем [Николина, 2009], его конвергенция с языком философии [Азарова, 2010], проводятся поэтические эксперименты [Имидж, диалог, эксперимент..., 2013].

Новизна нашего исследования состоит в том, что в нем с учетом взаимодействия уровней языка и с привлечением большого корпуса современных поэтических текстов (конца XX - начала XXI в.) выявляются те языковые структуры и ресурсы, которые делают возможным расширение сферы креативности в языке и определяют динамику его инноваций, то есть мы предлагаем изучение языка современной поэзии в аспекте языковой креативности - творческого и когнитивного потенциала, заложенного в языковых единицах, категориях и способах их репрезентации в целостном тексте. Такое понимание языковой креативности (лингвокреативности) связано с выделением, наряду с поэтической (эстетической), креативной (творческой) функции языка, детерминирующей пересмотр норм и традиций, отход от аналогии, создание новых форм и неожиданных сочетаний при передаче разнообразных мыслей и чувств.

Разработка темы лингвокреативности велась с установкой на работы В.В. Виноградова, в которых художественная речь, репрезентируемая в личностных формах, представлена как основная сфера индивидуально-речевого творчества [Виноградов, 2006], а также с учетом идеи Р. Якобсона о том, что творчество в языке связано с нарушением и преодолением конвенции системы [Якобсон, 2011, c. 34]. Методологически значимым для нашего исследования является и вывод Г.О. Вино- кура о том, что поэзия всегда связана с созданием языковых средств, которые «не даны непосредственно наличной традицией и вводятся как нечто совершенно новое в общий запас возможностей языкового выражения» [Винокур, 1943, с. 8]. Нами учитывались также результаты, полученные при исследовании других сфер языка (разговорной речи, детской речи, публицистики, медийного и рекламного дискурсов) [Ирисханова, 2009; Лингвистика креатива, 2009; Лингвистика креатива-2, 2012; Ремчукова, 2011; Carter, 2004; Creativity in Language and Literature..., 2011; Crystal, 1998; Maybin, Swann, 2007; Moreno, 2007; Pope, Swann, 2011; Vanderslice, 2011 и др.].

Особенность изучения проявлений языковой креативности в нашей работе заключается в том, что при их анализе учитывается фактор стихотворной формы, которая обусловливает возникновение упорядоченностей, не имеющихся в системе естественного языка (стихотворного размера, рифмы, звуковой организации, структурного параллелизма). Это позволило исследовать условия существования элементов поэтического текста, при которых возможности языковой системы проявляют себя наиболее полно. Еще одна особенность нашего исследования состоит в том, что обновление языковых средств в поэзии связано с каждым новым поэтическим поколением. С этой точки зрения активные процессы, происходящие в сфере языковой креативности, изучаются параллельно с происходящими в языке изменениями.

В центре нашего внимания в рамках данной статьи находились сферы словообразования, грамматики и лексики, языковые инновации в которых заставляют адресата сообщения искать причины выбора поэтом именно особого, неконвенционального способа выражения, открывающего новые пути словообразования и смыслообразования. Последнее связано с установкой поэтического языка на мо- 
тивированность всех типов девиаций (звуковых, орфографических, словообразовательных, грамматических, лексическо-семантических), поскольку в нем существует презумпция разрешения всех лингвистических аномалий. С этой точки зрения девиантность в поэзии - почти всегда осознанный авторский прием, который относится к метаязыковым явлениям: все введенные поэтом словообразовательные, грамматические, лексико-семантические и другие трансформации работают на приращение смысла, прежде всего на его эстетическую составляющую, а также на создание новых нетривиальных смыслов. Последнее и определяет креативный характер поэтических девиаций, которые в итоге становятся языковыми инновациями.

\section{Глагольные инновации}

1. Обратимся к окказиональным возвратным глагольным формам, демонстрирующим подвижность категорий залога и переходности на фоне общей обратимости субъектно-объектных синтаксических связей. Особенностью поэзии является специфическая имагинативная природа возвратных глаголов, поскольку, создавая поэтическое высказывание от «Я», поэт производит конверсию или трансформацию семантических ролей прежде всего в ментальной области - ведь в этом случае не существует заранее заданной референтной ситуации. Наоборот, грамматические сдвиги как раз порождают некоторую ранее не существовавшую расстановку актантов именно в ходе данного речементального поэтического события.

Необычные рефлексивные формы глагола со значением «постепенного убывания жизни» встречаем у В. Черешни:

\footnotetext{
Живешь, живешь, и обжигаешься вдруг ужасом, что не живешь, а потихоньку умираешься и полегоньку исчезаешься, не человек уже, а дрожь. $<\ldots>$

Пока наощупь разбираешься между «живешь» и «не живешь», скукоживаешься, смеркаешься, закатным отсветом теряешься, дня позолоченного грош.
}

Звуковая организация текста с аллитерацией на шипящие ж и $ш$ создает иконичность высказывания - она передает ощущение внутренней дрожи субъекта. В конце стихотворения используется безличный глагол смеркаешься, который в данном тексте обретает субъекта.

Инновации создаются и в случае, когда к возвратным глаголам присоединяются аффиксы, меняющие семантику исходного глагола на противоположную, при этом актантная структура сохраняется. См., например, стихотворение М. Амелина «Случайная музыка»:

$$
\begin{gathered}
\text { Нежно-розовый нехотя исчезает } \\
\text { под густо-лиловым,-- } \\
\text { зазеваешься, кажется, и не сыщешь } \\
\text { дороги туда, } \\
\text { где случайная музыка не успела } \\
\text { с умышленным словом }
\end{gathered}
$$

разминуться, развстретиться...

Присоединяя приставку раз- к возвратному глаголу встретиться, обозначающему взаимно-возвратное действие, поэт достигает оксюморонного эффекта - уничтожения «взаимности» и усиления семантики «разъединения» по отношению к разминуться.

Таким образом, можно констатировать, что в поэтической речи возвратность получает статус не только словоизменительной, но и словообразовательной категории, а возвратные глаголы образуют грамматические тропы, реализуя свой креативный потенциал.

В аспекте взаимодействия словообразования и словоизменения показательны случаи, когда поэты, экспериментируя с категорией возвратности, элиминируют возвратную частицу у возвратных глаголов. Так, Е. Шварц пишет:

Вот не думала, что доживу, дожду

До подгнивших слив в дрожжевом саду,

До августовской поворотной ночи, когда

Червь не минует ни одного плода.

Выстраивая глагольный ряд, автор лишает возвратности форму дождусь, отсекая постфикс -cь и отказывая этой форме в рефлексивности. Благодаря паронимической аттракции устанавливается «теснота стихового ряда», в рамках которой форма дожду получает то же управление, что и форма доживу (доживу, дожду до + род. п.; при этом не- 
Н.А. Фатеева. Грамматические инновации в современной поэзии как проявление лингвокреативности

возможно дождусь до). Выбор этой формы также диктуется рифмой.

2. В поэтическом языке нашего времени наблюдается особая тенденция образования глагольных форм императива, в которых слово- и формообразование взаимодействуют друг с другом. Так, П. Андрукович образует необычную глагольную форму солюби, обозначающую приглашение к совместному действию: солюби воздух с / кем-нибудь, кто / который / это сотворит / потом потом / задышит рыбка часто.

Существуют и формы императива, в которых новое значение обусловлено необычным управлением. Чаще всего это связано с появлением прямого объекта, что делает непереходный глагол переходным. Такие формы могут встраиваться в ряд стандартных императивов: Помолчи меня, полечи меня, поотмаливай. / Пролей на меня прохладный свой взор эмалевый. / Умой меня, замотай мне повязкой марлевой / Дурную, неостьваюшую башку (В. Полозкова), а могут быть и единичны: как мак и как память, замолчи меня (А. Глазова), но в том и другом случае в них обнаруживается семантика каузации. Аналогичное этому явление наблюдается и с глаголом сnать в форме повелительного наклонения, при том что каузация сна вряд ли возможна. Ср.: Не спи меня Не усыпай меня I Я сам заснусь засунусь в сновиде́нье (В. Строчков); Спите, листья, осень, спи нас (Н. Делаланд); в детство дорожденное, / в безмятежно-пенное / вещество без имени, / в сладкое «усни меня» (В. Черешня). В случае же, когда мы имеем дело с переходным глаголом, необычным в позиции прямого объекта является личное местоимение: наличие субъекта, самого продуцирующего высказывание: Изживай, избывай жеменя, бессмертный мой - / Так, как я тебя / изжила (В. Полозкова); Забывай, забывай обо мне, душа моя. / Ампутируй себе меня (В. Полозкова). Как видим, отличительным свойством всех этих форм является то, что трансформация их семантики связана с нестандартным управлением.

3. Появлению инноваций способствует и нетривиальное соединение приставки с производящей основой, не выражающей идеи перемещения. Так образован окказиональный глагол вмирать у Е. Шварц, который благодаря приставке в- приобретает семантику направленности «вовнутрь», закрепляющуюся формами винительного падежа с предлогом в (в тебя, в смерть):

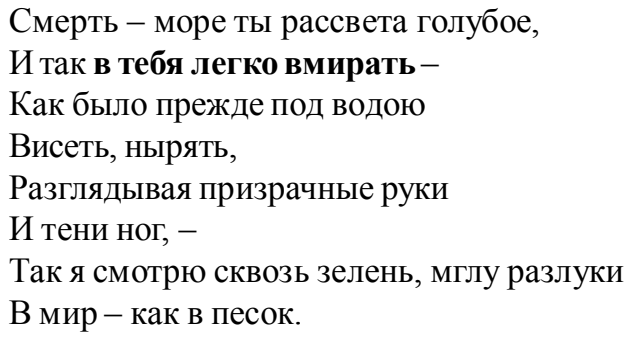

Нетривиальную семантику при присоединении приставки вы- со значением пространственной ориентированности к статическому глаголу обнаруживаем и у О. Пащенко, когда в контексте стиха ментальный глагол помнить приобретает направленность «наружу»:

Свет электричественный, золотой.

Он возвышается как пирамида над столом

с алкоголем, или без

алкоголя, только сидели

и никак ничего не могли

выпомнить из этой мглы.

4. Глагольные инновации проявляются в нетривиальном управлении. Например, возвратность может задаваться не только возвратной формой глагола, но и возвратным местоимением, при этом, например, у В. Строчкова она сопровождается указанием на направленность действия внутрь, не свойственную исходному статическому глаголу скучать:

\section{В окно глядеть, в себя скучать \\ и влизываться в даль, и трикопейки получать \\ за скудную печаль - \\ такая на челе печать \\ и участь. И пить чай.}

Аналогичная описанной семантическая трансформация обнаруживается и в случае, когда возвратный глагол сочетается с не совместимыми с его значением обстоятельствами. Так, у Н. Делаланд глагол проснуться наделяется свойствами глаголов направленного движения (куда?): 
Растворенную испей благодать.

В растворенные ворота войди.

Ты очнулся, ты проснулся сюда.

Ты в себе теперь. Пришел и в груди.

Таким образом, пространство сна осмысляется как внутреннее, из которого возможен выход, однако этот выход оказывается направленным в самого себя ( $T b l$ в себе menepb).

Направленность действия появляется и у глагола жить в поэтическом тексте С. Ивкина, однако точка назначения этого действия остается неопределенной благодаря субстантивированному наречию никуда:

Лишь осознав: человек - золотая пыльца, можно смириться, прорехи латая.

Да, я - всего лишь - пыльца,

но пыльца - золотая.

Я буду жить

в никуда,

не теряя

лица.

Н. Азарова, актуализируя направленность действия (признак, не свойственный ментальному глаголу забыть), заменяет возвратную форму забыться на забыть в себя:

заснуть - забыть в себя тяжелую таблетку легких

снов русский юль и русский юнь

\section{Адъективные инновации}

1. Полем для поэтического эксперимента оказываются окказиональные краткие прилагательные, прежде всего относительные. Например, М. Степанова образует целый ряд кратких прилагательных от названий дней недели: День понеделен, вторничен, срединн, / Чист как паркет, пока не наследим. Расширяет эту парадигму Н. Азарова, в нее попадают также неологизмы летен и диванн, характеризующие знойный день: день - зноен - летен - и срединн / диванн - впадением в болезнь. Форма зноен редко, но употребляется в поэзии. Ср. у Тэффи: $О н$ был так зноен, мой прекрасный день! / И два ияет-

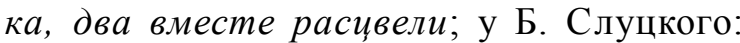
Июнь был зноен. Январь был зябок. / Бетон был прочен. Подобные формы встречаем также у А. Костинского: Небосвод одновременно зимен, летен и осен, и еще у Н. Азаровой: то мои неупорные предрассудки / всласть демисезонны.

У В. Полозковой встречаем более сложный случай: Речь пряна и альма-матерна nо уму. Во-первых, данный контекст отражает тенденцию употребления окказиональных кратких форм прилагательных в одном ряду с нормативными согласно аналогии, так как в ряду могут быть прилагательные одной формы. Во-вторых, в альма-матерна мы имеем дело с наложением и контаминацией слов альма-матер (так в речи выпускников называется университет или вуз) и матерньй 'нецензурый', второе из которых принимает форму краткого прилагательного. Возможно и образование от прилагательного альма-матерный, непосредственно произведенного от альма-матер. Хотя такое слово в словарях не представлено, в интернете находим название книги «Альма-матерная жизнь» О.П. Рыжкова, которая повествует о жизни студентов.

2. В поэтических произведениях современных авторов встречаются формы сравнительной степени прилагательных, образованных от существительных, числительных, а также от любых прилагательных, которые в обычном языке ее не образуют. Такие формы сравнительной степени прилагательного, образованные от существительного дрова, находим у А. Еременко: Колю дрова / напротив бензоколонки. / Меня смущает столь откровенное сопоставление / полена, поставленного на попа, / и «кола» в «колонке». / Я пытаюсь вогнать между ними клин, / я весь горю, / размахиваюсь... <..> Но с каждым ударом меня сносит влево, / и я становлюсь все дровее и дровее. Н. Азарова для своей поэтической зарисовки выбирает море, ветер и горы, которые различаются по степени проявления признака: лезут подгоревшие сумерки / еще морей / еще ветрей / еще горей / куда уж.

В поэтическом тексте образование форм сравнительной степени приобретает некоторую свободу и, как и в разговорной речи, они производятся от любых прилагательных. Так, у Ю. Мориц сравнительную степень образуют относительные прилагательные: 
Н.А. Фатеева. Грамматические инновации в современной поэзии как проявление лингвокреативности

Снег на исходе дня

делается небесней.

Кто-то промчался с песней,

Сделанной из меня;

Боялся без вести пропасть

В столице медленных событий.

Дразнил дряхлеющую власть,

Боясь, что будет всех забытей.

Сравнительную степень образуют и прилагательные с суффиксом -к-: Беда никогда не приходит одна. / Обычно она дерзей. / Беда приносит с собой вина, / Приводит с собой друзей (В. Полозкова); И не знаешь, которая рожа мерзей, - / То ли враг, размалеванный краской, / То ли пестрые глазки недавних друзей / Под небрежно наброшенной маской... (М. Саввиных).

У В. Полозковой находим сравнительную степень прилагательного, образованную даже от числительного один:

То, к чему труднее всего привыкнуть -

Я одна, как смертник или рыбак.

Я однее тех, кто лежит, застигнут

Холодом на улице: я слабак.

Я одней всех пьяниц и всех собак.

Ты умеешь так безнадежно хмыкнуть,

Что, похоже, дело мое табак.

Представлена также и форма сравнительной степени от прилагательного одинокий. Ее мы встречаем у В. Черешни наряду с другими окказиональными образованиями:

В этом просторе надышанном

Днем ли, тягучею ночью ли,

Кем бы ты ни был услышанным,

Можно ль еще одиночее?

Можно ль еще одичалее

Глубже вдыхать и любимее

Воздух, который печалили,

Столько родного без имени?

\section{Инновации, возникающие \\ в результате образования от местоимений существительных}

Отличительной чертой современной поэзии является то, что образование дериватов может происходить от таких частей речи, которые не участвуют в словообразовании. Это в первую очередь касается местоименных основ.
Подобные производные специфичны для В. Полозковой. Так, в стихотворении «Я твой щен: я скулю, я тычусь в плечо незряче...» поэтесса характеризует свое состояние разлуки с любимым: Я картограф твой: глаз Атлантикой, скулу - степью, / A затылокполярным кругом: там льды; that'sit. / Я ученый: мне инфицировали бестебье. / Тебядефицит. Первое производное образовано от предложной формы без тебя по модели существительного безрыбье, второе - голофрастическое слитное образование - сформировано по типу сращения (тебядефицичт). В обоих случаях можно говорить не только о словообразовательной деривации, но и об образовании особого типа отместоименных существительных.

У В. Полозковой находим также пример образования сложного существительного, первой частью которого является падежная форма личного местоимения: Я тебя таскаю в венах, как похмельный тебяголик, / Все еще таскаю в венах. Осторожней, мой соколик (существительное тебяголик создано по типу алкоголик, трудоголик). В современном языке данная словообразовательная парадигма весьма продуктивна. Ср.: геймоголик, сетеголик, загароголик и др. (см.: [Руденко, 2011]). В произведениях поэтессы обнаруживается большое количество подобных дериватов не только от личных местоимений, но и от относительных, вопросительных, притяжательных и неопределенных. Имеется даже подборка стихотворений под названием «Чьятость», смысл которого разъясняется в тексте строками стихотворения «Оглушительная твоязнь»: Лишь бы билась внутри, как пульс, нутряная чьятость. / Долгожданная, оглушительная твоязнь. Для словообразования поэтессой выбраны местоимения женского рода (чья, твоя); оба производных допускают две мотивации. Дериват чьятость создан при помощи суффикса -ость, свойственного абстрактным существительным, и интерфикса - $m$ - или образован от неопределенного местоимения чья-то. Дериват твоязнь это контаминация притяжательного местоимения твоя и существительного боязнь, хотя возможна и прямая деривация от местоимения при помощи суффикса -знь, который представлен в ограниченном числе слов (боязнь, 
болезнь, жизнь), форма твоязнь, встраиваясь в эту парадигму, обрастает семантическими связями со всеми тремя существительными. Следовательно, твоязнь соотносится с такими проявлениями жсизни, как болезнь и боязнь, хотя актуализация таких связей, возможно, и не входила в замысел поэтессы.

В. Полозкова создает слова по типу сращения, когда дефис служит показателем соединения местоименной и именной основ, например: Первой истошной паникой по утрам - / Как себя вынести, / Выместить, вымести; / Гениям чувство кем-то-любимости - / Даже вот Богом при входе в храм-/ Дорого: смерть за грамм. Более того, у поэтессы несклоняемые местоимения начинают склоняться, как существительные: Чтоб тут же сделаться такой, / Какой мечталось - без синекдох, / Единой, а не в разных нектах; / Замкнуться; обрести покой.

\section{Заключение}

Обнаруженные нами продуктивность и парадигматичность выше проанализированных новообразований позволяют утверждать, что модели их деривации потенциально заложены в языке, это дает возможность каждому из них реализовывать себя в индивидуально-авторских формах.

Следует также отметить особенности восприятия этих форм читателем. Как пишет Т.В. Устинова, «языковые девиации субъективно воспринимаются читателем как обладающие разной степенью нестандартности / девиантности и располагаются в диапазоне от «“совершенно не интерпретируемых" авторских новообразований, вызывающих коммуникативный шок, до “не вызывающих трудностей интерпретации” мотивированных отклонений, потенциально развивающих возможности, заложенные языковой системой» [Устинова, 2014]. Можно сказать, что чем выше креативный потенциал нестандартной языковой формы, тем она менее окказиональна. Это означает, что рефлексивные векторы языковой личности поэта и рефлексивные векторы языковой личности читателя относительно этой формы однонаправленны и вместе работают на расширение эстетических возможностей языка. Задача же лингвиста как читате- ля-исследователя - «не только изучать художественную словесность, но и вносить ее творческий потенциал в общенародный язык, находить те лексические и грамматические формы, которые оживлены гением поэта и могут в свою очередь заново пробуждать гений языка» [Эпштейн, 2013].

Наше исследование подтверждает, что языковая креативность является особой категорией лингвистической поэтики как области изучения тех индивидуально-авторских преобразований в области художественной речи, которые служат основой обновления и расширения самой системы поэтического языка.

\section{СПИСОК ЛИТЕРАТУРЫ}

Азарова Н. М., 2010. Язык философии и язык поэзии: движение навстречу. М. : Гнозис. 496 с.

Виноградов В. В., 2006. Социально-языковые системы и индивидуально-языковое творчество. Семиотика и Авангард: Антология / под общ. ред. Ю. С. Степанова. М. : Культура : Академ. Проект. С. 242-250.

Винокур Г. О., 1943. Маяковский - новатор языка. М. : Сов. писатель. 136 с.

Зубова Л. В., 2000. Современная русская поэзия в контексте истории языка. М. : НЛО. $431 \mathrm{c}$.

Зубова Л. В., 2010. Языки современной поэзии. М. : НЛО. $384 \mathrm{c}$.

Имидж, диалог, эксперимент..., 2013. Имидж, диалог, эксперимент - поля современной русской поэзии / ред. Х. Шталь, М. Рутц. München ; Berlin ; Washington D. C. : Verlag Otto Sagner. $600 \mathrm{c}$.

Ирисханова О. К., 2009. О понятии креативности и его роли в метаязыке лингвистических описаний // Когнитивные исследования языка. М. : Ин-т языкознания ; Тамбов : Тамб. гос. ун-т им. Г.Р. Державина. Вып. V. С. 157-171.

Лингвистика креатива, 2009. Лингвистика креатива : колл. моногр. / отв. ред. Т. А. Гридина. Екатеринбург : Урал. гос. пед. ун-т. 368 с.

Лингвистика креатива-2, 2012. Лингвистика креатива-2 : колл. моногр. / под общ. ред. проф. Т. А. Гридиной. 2-е изд. Екатеринбург : Урал. гос. пед. ун-т. 379 с.

Николина Н. А., 2009. Активные процессы в языке современной русской художественной литературы. М. : Гнозис. 335 с.

Ремчукова Е. Н., 2011. Креативный потенциал русской грамматики. М. : URSS. 224 c.

Руденко О. Ю., 2011. Неологизмы и новообразования как показатели активности иноязычности 
в современном русском языке // Вестник Нижегородского государственного университета им. Н.И. Лобачевского. № 6 (2). С. 589-592.

Устинова Т. В., 2014. Языковые девиации поэта как код и сообщение // Universum: Филология и искусствоведение : электрон. науч. журн. № 3 (5). URL: http://7universum.com/ru/philology/ archive/item/1123 (дата обращения: 01.04.2017).

Эпштейн М. Н., 2013. О роли лингвистики в развитии языка. URL: http://www.mccme.ru/llsh/ materials/2013/Epstein_Iazyk_letn_shkolaF.pdf (дата обращения: 01.04.2017).

Якобсон Р. О., 2011. Формальная школа и современное русское литературоведение. М. : Языки славянских культур. 280 с.

Carter R., 2004. Language and Creativity. The Art of Common Talk. London : Routledge. 255 p.

Creativity in Language and Literature..., 2011. Creativity in Language and Literature: The State of the Art / Swann J., Pope R., Carter R., eds. Basingstoke : Palgrave Macmillan. $368 \mathrm{p}$.

Crystal D., 1998. Language Play. Harmondsworth : Penguin. 249 p.

Maybin J., Swann J., 2007. Everyday Creativity in Language: Textuality, Contextuality, and Critique // Applied Linguistics. Vol. 28, iss. 4. P. 497-517.

Moreno R., 2007. Creativity and Convention: The Pragmatics of everyday figurative speech. Amsterdam : John Benjamins. 249 p.

Pope R., Swann J., 2011. Introduction: creativity, language, literature // Creativity in Language and Literature: The State of the Art / Swann J., Pope R., Carter R., eds. Basingstoke : Palgrave Macmillan. P. 217-230.

Vanderslice S., 2011. Creative Writing Studies: Rethinking Creative Writing: Programs and Practices that Work. Wicken, Cambridgeshire: CWS. 152 p.

\section{REFERENCES}

Azarova N.M., 2010. The language of philosophy and the language of poetry: the movement towards each other. Moscow, Gnozis Publ. 496 p.

Vinogradov V.V., 2006. The socio-language systems and individual-linguistic creativity. Stepanov Yu.S. (ed.) Semiotika i Avangard: Antologiya. Moscow, Akademicheskiy proekt Publ., pp. 242-250.

Vinokur G.O., 1943. Mayakovsky is the innovator of language. Moscow, Sov. pisatel Publ. 136 p.

Zubova L.V., 2000. Modern Russian poetry in the context of the history of language. Moscow, NLO Publ. $431 \mathrm{p}$.

Zubova L.V., 2010. The languages of modern poetry. Moscow, NLO Publ. 384 p.
Stahl H., Rutz M. (eds.), 2013. Image, dialogue, experiment - the fields of modern Russian poetry. München; Berlin; Washington D.C., Verlag Otto Sagner. $600 \mathrm{p}$.

Iriskhanova O.K., 2009. On the concept of creativity and its role in the metalanguage of linguistic descriptions. Kognitivnye issledovaniya yazyka [Cognitive Studies of Language]. Moscow, In-t yazykoznaniya Publ.; Tambov, Tambovskiy gos. un-t im. G.R. Derzhavina, iss. 5, pp. 157-171.

Gridina T.A. (ed.), 2009. The linguistics of creativity. Collective monograph. Ekaterinburg, Izd-vo UGPU. 368 p.

Gridina T.A. (ed.), 2012. The linguistics of creativity. Part 2. Collective monograph. Ekaterinburg, Izd-vo UGPU. 379 p.

Nikolina N.A., 2009. The active processes in the language of contemporary fiction. Moscow, Gnozis Publ. 335 p.

Remchukova E.N., 2011. The creative potential of Russian grammar. Moscow, URSS Publ. 224 p.

Rudenko O.Yu., 2011. Neologisms and new formations as indicators of the foreign-language activity in the modern Russian language. Vestnik Nizhegorodskogo gosudarstvennogo universiteta im. N.I. Lobachevskogo [Vestnik of Lobachevsky University of Nizhni Novgorod], no. 6 (2), pp. 589-592.

Ustinova T.V., 2014. Language deviations in poetry as a code and a message. Universum: Filologiya $i$ iskusstvovedenie: elektron. nauchn. zhurn., no. 3 (5). URL: http://7universum.com/ru/ philology/archive/item/1123. (accessed 1 April 2017).

Epshteyn M.N., 2013. On the role of linguistics in the development of language. URL: http://www. mccme.ru/1lsh/materials/2013/Epstein Iazyk_letn_shkolaF.pdf. (accessed 1 April 2017).

Yakobson R.O., 2011. The school of formalism and modern Russian literary criticism. Moscow, Yazyki slavyanskikh kultur Publ. 280 p.

Carter R., 2004. Language and Creativity. The Art of Common Talk. London, Routledge. 255 p.

Swann J., Pope R., Carter R. (eds.), 2011. Creativity in Language and Literature: The State of the Art. Basingstoke, Palgrave Macmillan. 368 p.

Crystal D., 1998. Language Play. Harmondsworth, Penguin. 249 p.

Maybin J., Swann J., 2007. Everyday Creativity in Language: Textuality, Contextuality, and Critique. Applied Linguistics, vol. 28, iss. 4, pp. 497-517.

Moreno R., 2007. Creativity and Convention: The Pragmatics of everyday figurative speech. Amsterdam, John Benjamins. 249 p.

Pope R., Swann J., 2011. Introduction: creativity, language, literature. Swann J., Pope R., Carter R. 
(eds.) Creativity in Language and Literature: The State of the Art. Basingstoke, Palgrave Macmillan, pp. 217-230.
Vanderslice S., 2011. Creative Writing Studies: Rethinking Creative Writing: Programs and Practices that Work. Wicken, Cambridgeshire, CWS. 152 p.

\section{Information about the Author}

Natalya A. Fateeva, Doctor of Sciences (Philology), Chief Researcher, V.V. Vinogradov Russian Language Institute, Russian Academy of Sciences, Volkhonka St., 18/2, 119019 Moscow, Russia, nafata@rambler.ru, https://orcid.org/0000-0003-0916-1161

\section{Информация об авторе}

Наталья Александровна Фатеева, доктор филологических наук, главный научный сотрудник, Институт русского языка им. В.В. Виноградова РАН, ул. Волхонка, 18/2, 119019 г. Москва, Россия, nafata@rambler.ru, https://orcid.org/0000-0003-0916-1161 